\title{
Brain creatine kinase in blood after acute brain injury
}

\author{
HANNU SOMER ${ }^{1}$, MARKKU KASTE, HENRY TROUPP, \\ AND AARNE KONTTINEN \\ From the Wihuri Research Institute, Helsinki, the Neurosurgical Clinic, \\ University Central Hospital, Helsinki, and the Department of Neurology, \\ University Central Hospital, Helsinki, Finland
}

SYNOPSIS Severe cold injury of the brain increased significantly both total creatine kinase and the corresponding brain isoenzyme $\left(\mathrm{CK}_{\mathrm{BB}}\right)$ activity in confluens sinuum samples. $\mathrm{CK}_{\mathrm{BB}}$ could be detected also in peripheral blood a few hours after severe brain injury in eight of 12 patients. Finding of $\mathrm{CK}_{\mathrm{BB}}$ in human plasma may prove a useful indicator of severe brain injury.

Acute tissue damage usually releases intracellular enzymes into the circulation. Acute brain damage is followed by increased creatine kinase (CK) activity in the serum (Acheson et al., 1965; Langton et al., 1967; Eisen and Sherwin, 1968; Wolintz et al., 1969). Efforts to determine the source of increased CK activity have given surprising results: typical brain tissue isoenzyme, $\mathrm{CK}_{\mathrm{BB}}$, has not been found at all in the serum. Rather the increased total CK activity was composed of the isoenzymes of skeletal muscle and heart; $\mathrm{CK}_{\mathrm{MM}}$ and $\mathrm{CK}_{\mathrm{MB}}$ (Dubo et al., 1967; Cao et al., 1969). Serum enzyme diagnosis has therefore been considered useless for the diagnosis of brain damage.

New and more sensitive CK isoenzyme methods have been developed (Roe et al., 1972; Somer and Konttinen, 1972) offering new possibilities for organ specific enzyme analysis (Klein et al., 1973; Konttinen and Somer, 1973; Somer et al., 1973). We therefore studied whether these more refined methods would reveal release of $\mathrm{CK}_{\mathrm{BB}}$ into blood after acute brain injury in both experimental animals and in human cases.

\section{METHODS}

EXPERIMENTAL SERIES Healthy rabbits were used. The first blood sample was taken from an auricular vein (BA sample) and the animals were then anaes-

1 Address for reprints: Dr H. Somer, The Wihuri Research Institute, Kalliolinnantie 4, 00140 Helsinki 14, Finland.

(Accepted 27 January 1975.) thetized with 30-35 mg sodium pentobarbitone (Nembutal) per $\mathrm{kg}$ body weight. Atropine was always used. Local anaesthesia for tracheostomy was induced with a $1-2 \%$ solution of prilocaine (Citanest). The animals breathed spontaneously throughout the experiment. Procaine penicillin (300 000 iu) was given intraperitoneally to prevent wound infection. Peripheral blood samples were taken through a catheter inserted into a jugular vein with the cephalad end of the vessel ligated. For cerebral blood samples a cannula was attached to the confluens sinuum (Troupp et al., 1966). One peripheral and one cerebral sinus sample were taken immediately after the surgical preparation was completed (AP sample). A funnel with a diameter of $15 \mathrm{~mm}$ was attached to the left of the sagittal suture of the rabbit skull, just behind the coronary suture. A severe cold injury was induced in 15 animals by pouring liquid nitrogen into the funnel (Kaste and Troupp, 1972). The freezing time was one and a half minutes. Blood samples were drawn three, six, and 12 hours after the injury. Twelve control animals underwent all procedures except the brain injury.

CLINICAL SERIES Twelve patients with severe brain injury suffered within the previous eight hours, and seven patients undergoing neurosurgical operations were studied (see Table 2). The indications for the neurosurgical procedures were: middle cerebral aneurysm (two patients), deep meningioma (two patients), malignant intracerebral tumour (two patients), and one acoustic neuroma. In all instances there was some trauma to brain tissue during the operation. Serial peripheral blood samples were taken, but a rigid time schedule could not always be achieved with the brain injured patients. 
TABLE 1

PLASMA TOTAL CK AND $\mathrm{CK}_{\mathrm{BB}}$ ISOENZYME ACTIVITY AFTER EXPERIMENTAL BRAIN INJURY*

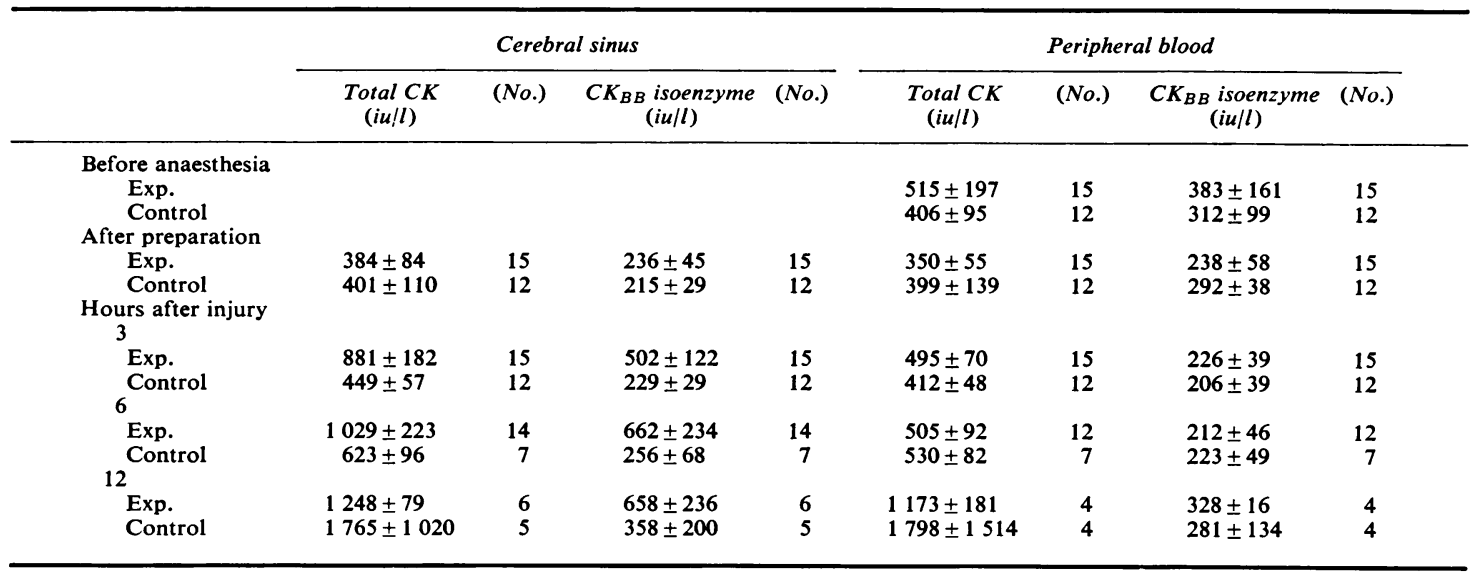

* Mean $\pm S E ;$ no. $=$ number of samples.

TABLE 2

PLASMA CREATINE KINASE ISOENZYMES IN CLINICAL BRAIN INJURY

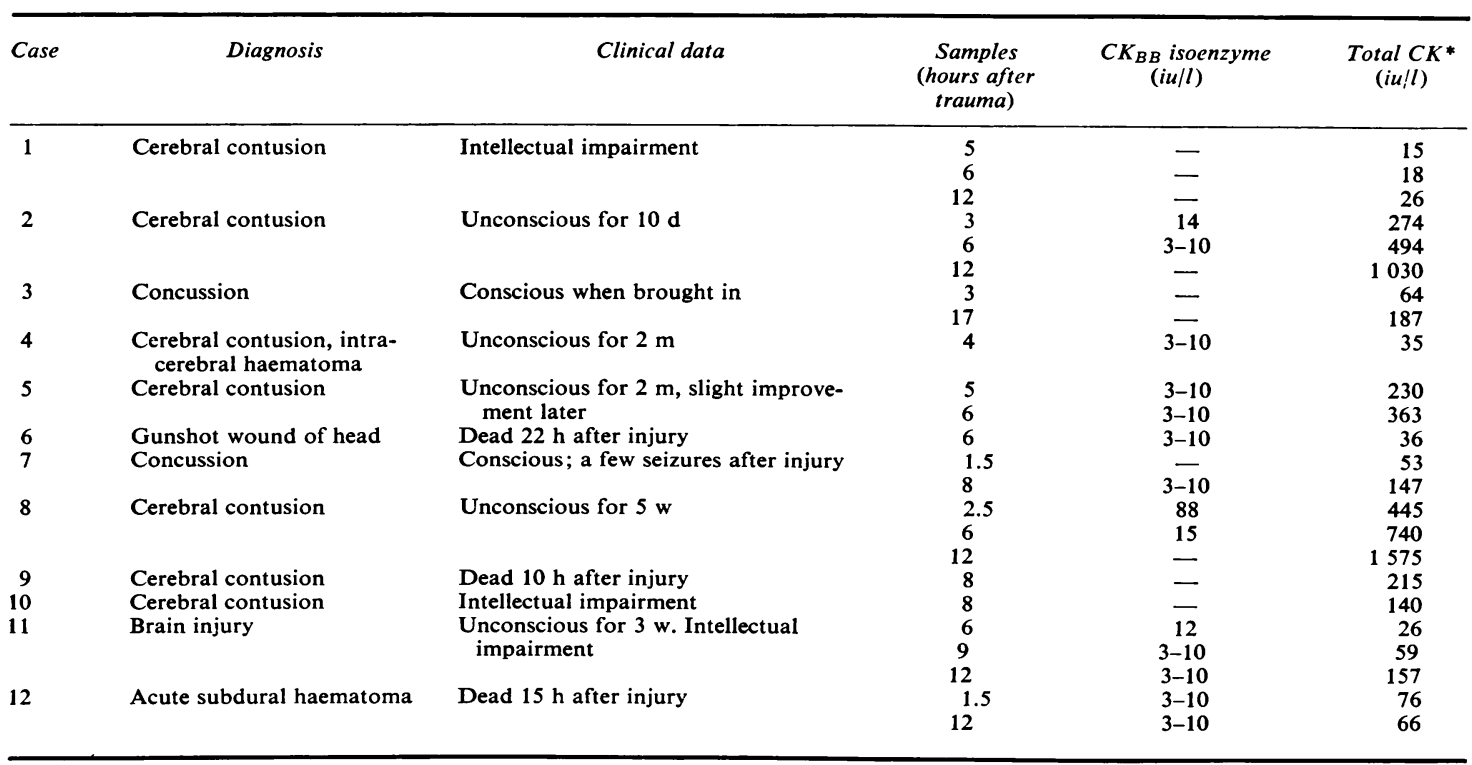

* Normal values for total CK: 0-50 iu/1. 
BIOCHEMICAL METHODS Blood samples were taken into heparinized tubes. Some haemolysis occurred in most tubes. Glutathione was added to achieve a $10 \mathrm{mmol} / \mathrm{l}$ concentration in plasma. The samples were either analysed immediately or stored at $-20^{\circ} \mathrm{C}$ and analysed within two months.

Total CK activity was measured by means of test kits (CPK activated, Boehringer, Mannheim), with a normal range of $0-50 \mathrm{iu} / 1$ in human plasma. Creatine kinase isoenzymes were separated electrophoretically and determined by a fluorescence technique (Somer and Konttinen, 1972). ${ }^{2}$ The method detects an isoenzyme of 3-5 iu/l. A linear quantitation is achieved within 10-250 iu/1, if a short incubation time $(0.5 \mathrm{~h})$ is used. For higher activities corresponding dilutions were made. The results are expressed as $\mathrm{CK}_{\mathrm{BB}}$ activity (iu/l).

\section{RESULTS}

The cold injury caused a rapid rise in CK activity in cerebral sinus blood. Within three hours total CK activity rose by $397 \mathrm{iu} / 1$ in the injury group but only by $48 \mathrm{iu} / 1$ in the control group. The difference is statistically significant

2 The published method contains an error: incubation fluid should contain also $40 \mathrm{mg}$ glucose in $5 \mathrm{ml}$ glycylglycine buffer in addition to the other reagents mentioned.

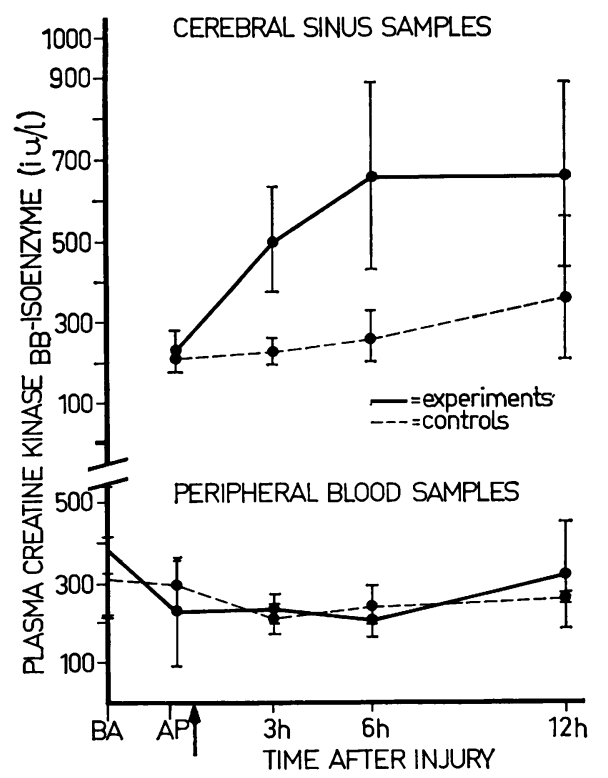

FIG. 1 Plasma creatine kinase $_{B B}$ isoenzyme levels (mean $\pm S E M)$ in the rabbit after a severe local freeze injury to the brain.
( $\mathbf{P}<0.01$, Student's $t$ test). The rise is mainly due to $\mathrm{CK}_{\mathrm{BB}}$ activity, which rose by $266 \mathrm{iu} / 1$ in the injury group and by only $14 \mathrm{iu} / 1$ in the control group $(\mathrm{P}<0.02)$. The highest $\mathrm{CK}_{\mathrm{BB}}$ values were seen in the six hour and 12 hour samples from the confluens sinuum. No rise in $\mathrm{CK}_{\mathrm{BB}}$ activity was observed in peripheral blood samples collected at the same time (Fig. 1, Table 1).

Peak total CK activity was measured at 12 hours. The animals surviving this long showed a wide scatter in enzyme values and no clear difference was noted between experimental and control animals, either in cerebral sinus or in peripheral blood samples. $\mathrm{CK}_{\mathrm{MM}}$, the isoenzyme of skeletal and heart muscle, was usually responsible for high total $\mathrm{CK}$ values in the 12 hour samples.

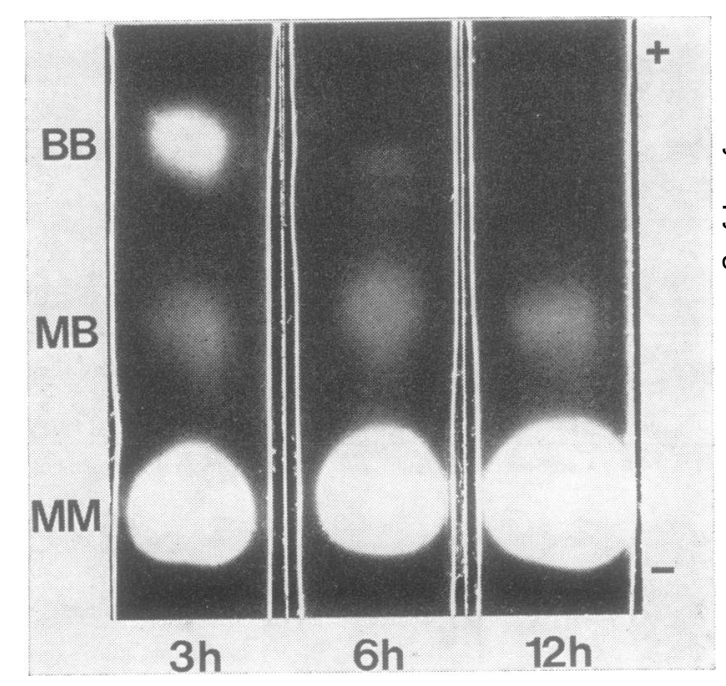

FIG. 2 Plasma creatine kinase isoenzyme in a patient with cerebral contusion. The $C K_{B B}$ isoenzyme is typical of brain tissue, and $C K_{M B}$ and $C K_{M M}$ are typical of heart and skeletal muscle. The first sample (left) was taken 2.5 hours after the injury. Total CK activity was $445 \mathrm{iu} / \mathrm{l}$ (normally less than $50 \mathrm{iu} / \mathrm{l}$ ), and $C K_{B B}$ made up $20 \%$ of the total $C K$ activity. The second sample (middle) was taken six hours after the injury. Total $C K$ activity was $740 \mathrm{iu} / \mathrm{l}$, and $C K_{B B}$ was still visible. The third sample (right) was taken 12 hours after the injury. Total CK activity was 1575 iull, and $C K_{B B}$ could no longer be demonstrated. 
CLINICAL In patients with acute brain injury $\mathrm{CK}_{\mathrm{BB}}$ isoenzyme was found in peripheral blood in eight of 12 patients. All eight patients had had severe brain injury, usually a cerebral contusion, causing severe disturbance of consciousness (Table 2). $\mathrm{CK}_{\mathrm{BB}}$ activity was usually at its peak in the first sample and then disappeared quickly (Fig. 2). At most it was $23 \%$ of total CK activity. The peak total CK activity was found later when there was little or no $\mathrm{CK}_{\mathrm{BB}}$ activity. No $\mathrm{CK}_{\mathrm{BB}}$ activity was demonstrated in samples collected after the neurosurgical operations.

\section{DISCUSSION}

In the experimental rabbits the rise in total CK activity in cerebral venous blood was largely due to $\mathrm{CK}_{\mathrm{BB}}$ activity, the isoenzyme which occurs mainly in the brain. Peripheral blood did not show this rise in $\mathrm{CK}_{\mathrm{BB}}$ activity; perhaps the amount of $\mathrm{CK}_{\mathrm{BB}}$ released from the damaged brain was too small to cause an appreciable rise in $\mathrm{CK}_{\mathrm{BB}}$ in pooled peripheral blood. The rise of $\mathrm{CK}_{\mathrm{BB}}$ in cerebral venous blood alone, and not in pooled peripheral blood, excludes lungs, spleen, kidneys, red muscle or thyroid as sources of this $\mathrm{CK}_{\mathrm{BB}}$, although in the rabbit these organs contain some $\mathrm{CK}_{\mathrm{BB}}$ (Brody and Hatcher, 1967; Sherwin et al., 1967). Total CK activity increased in quite a few samples of both cerebral and pooled peripheral blood 12 hours after injury, but this was due to a rise in $\mathrm{CK}_{\mathrm{MM}}$ or $\mathrm{CK}_{\mathrm{MB}}$, the isoenzymes presumably released by surgical trauma, anaesthesia, or impaired ventilation (Dixon et al., 1971; Phornphutkul et al., 1974).

The clinical results tally with the experimental ones. Some $\mathrm{CK}_{\mathrm{BB}}$ is released from brain to blood soon after a severe brain injury. Since normal human plasma does not show any $\mathrm{CK}_{\mathrm{BB}}$ activity, small amounts can easily be detected in analyses of peripheral blood. To find $\mathrm{CK}_{\mathrm{BB}}$ in peripheral blood after clinical brain injury requires a sensitive method as well as well-timed sampling. The fluorescence technique (Somer and Konttinen, 1972) is clearly more sensitive than the methods used in previous studies (Dubo et al., 1967; Cao et al., 1969). When present, $\mathrm{CK}_{\mathrm{BB}}$ isoenzyme could usually be detected even in the earliest samples collected. No association between the presence of $\mathrm{CK}_{\mathrm{BB}}$ and total $\mathrm{CK}$ activity could be observed. This again shows the uselessness of total $\mathrm{CK}$ measurements as an indicator of brain damage.

The clinical value of plasma $\mathrm{CK}_{\mathrm{BB}}$ determinations has so far not been determined. Although $\mathrm{CK}_{\mathrm{BB}}$ occurs in some other human organs too (Dawson and Fine, 1967), it has not been found previously in human plasma in any other clinical conditions except in a few cases of malignant hyperpyrexia (Zsigmond and Starkweather, 1973). It seems that a severe injury is needed to cause the release of $\mathrm{CK}_{\mathrm{BB}}$ into peripheral blood and so, when it does, this may possibly offer new criteria for the early assessment of the severity of brain damage.

This study was supported by the Sigrid Jusélius Foundation Finland and the Medical Research Council in the Academy of Finland.

\section{REFERENCES}

Acheson, J., James, D. C., Hutchinson, E. C., and Westhead, R. (1965). Serum-creatine-kinase levels in cerebral vascular disease. Lancet, 1, 1306-1307.

Brody, I. A., and Hatcher, M. A. (1967). Origin of increased serum creatine phosphokinase in tetanus. Archives of Neurology, 16, 89-93.

Cao, A., Virgiliis, S. de, Lippi, C., and Trabalza, N. (1969). Creatine kinase isoenzymes in serum of children with neurological disorders. Clinica Chimica Acta, 23, 475-478.

Dawson, D. M., and Fine, I. H. (1967). Creatine kinase in human tissues. Archives of Neurology, 16, 175-180.

Dixon, S. H., Jr, Fuchs, J. C. A., and Ebert, P. A. (1971). Changes in serum creatine phosphokinase activity following thoracic, cardiac, and abdominal operations. Archives of Surgery, 103, 66-68.

Dubo, H., Park, D. C., Pennington, R. J. T., Kalbag, R. M. and Walton, J. N. (1967). Serum-creatine-kinase in cases of stroke, head injury, and meningitis. Lancet, 2, 743-748.

Eisen, A. A., and Sherwin, A. L. (1968). Serum creatine phosphokinase activity in cerebral infarction. Neurology (Minneap.), 18, 263-268.

Kaste, M., and Troupp, H. (1972). Effect of experimental brain injury on blood pressure, cerebral sinus pressure, cerebral venous oxygen tension, respiration, and acid-base balance. Journal of Neurosurgery, 36, 625-633.

Klein, M. S., Shell, W. E., and Sobel, B. E. (1973). Serum creatine phosphokinase (CPK) isoenzymes after intramuscular injections, surgery, and myocardial infarction. Cardiovascular Research, 7, 412-418.

Konttinen, A., and Somer, H. (1973). Specificity of serum creatine kinase isoenzymes in diagnosis of acute myocardial infarction. British Medical Journal, 1, 386-389.

Langton, L., Moxon, C. P., Riddoch, D., Westhead, R. A., and Woolf, A. L. (1967). Jugular bulb creatine kinase as an indication of slight transient brain damage. Lancet, 2, 278-281.

Phornphutkul, K. S., Anuras, S., Koff, R. S., Seeff, L. B., Mahler, D. L., and Zimmerman, H. J. (1974). Causes of increased plasma creatine kinase activity after surgery. Clinical Chemistry, 20, 340-342. 
Roe, C. R., Limbird, L. E., Wagner, G. S., and Nerenberg, S. T. (1972). Combined isoenzyme analysis in the diagnosis of myocardial injury: application of electrophoretic methods for the detection and quantitation of the creatine phosphokinase MB isoenzyme. Journal of Laboratory and Clinical Medicine, 80, 577-590.

Sherwin, A. L., Siber, G. R., and Elhilali, M. M. (1967). Fluorescence technique to demonstrate creatine phosphokinase isozymes. Clinica Chimica Acta, 17, 245-249.

Somer, H., and Konttinen, A. (1972). Demonstration of serum creatine kinase isoenzymes by fluorescence technique. Clinica Chimica Acta, 40, 133-138.

Somer, H., Donner, M., Murros, J., and Konttinen, A. (1973). A serum isozyme study in muscular dystrophy. Particular reference to creatine kinase, aspartate amino- transferase, and lactic acid dehydrogenase isozymes. Archives of Neurology, 29, 343-345.

Troupp, H., Kaste, M., Kuurne, T., and Huttunen, M. (1966). Experimental cerebral venous oxygen tension during raised intracranial pressure. Journal of Neurosurgery, 25, 638-642.

Wolintz, A. H., Jacobs, L. D., Christoff, N., Solomon, M., and Chernik, N. (1969). Serum and cerebrospinal fluid enzymes in cerebrovascular disease. Creatine phosphokinase, aldolase, and lactic dehydrogenase. Archives of Neurology, 20, 54-61.

Zsigmond, E. K., and Starkweather, W. H. (1973). Abnormal serum and muscle creatine phosphokinase (CPK) isoenzyme pattern in a family with malignant hyperthermia. Anaesthesist, 22, 16-22. 